\section{MISMANAGEMENT OF THE EYES OF READERS.}

BY NORBURNE B. JENKINS, M.D.

The exact fitting of reading lenses to the eyes of studiously inclined persons past middle age, is either one of the most simple or one of the most complicated things that the oculist is ever called upon to do. In the absence of astigmatism and of a difference in the refraction of the eyes, the fitting of reading lenses is a matter of no difficulty. When there exists $0.5 \mathrm{D}$. or more of astigmatism in one or both eyes, and a difference of $0.25 \mathrm{D}$. or more in the refraction of the eyes perfectly fitting lenses for reading are seldom obtained.

Commonly but little care is given to the fitting of reading lenses to the eyes of persons above 40 years of age. Ordinarily the weakest convex lenses with which the patient is able to read the smallest print at a distance of $22 \mathrm{~cm}$. (8.5 inches) from the eyes, are prescribed. In many cases such lenses can not be used with comfort.

For the sake of economy the shopkeeper is frequently the first to be visited by the sufferer with "failing eyesight." Here he is usually given glasses of a number supposed to correspond with his age, or frequently the customer selects for himself such glasses as will improve the near vision, which is often at the expense of comfort. In the absence of astigmatism of $0.5 \mathrm{D}$. or more, and a difference of $0.25 \mathrm{D}$. or more in the refraction of the eyes, for a shilling the purchaser may obtain perfectly fitting reading glasses, provided they are sufficiently weak.

The comfort to be derived from perfectly fitting reading lenses is best understood by persons, who by using them, are enabled to read for hours without inconvenience. The evil consequences of the persistent use of imperfectly fitting reading glasses are many, and include asthenopia and amblyopia. The persons, who, by reason of improper glasses, use but one eye in reading, are more numerous than is gen. erally supposed.

Provided there is present no disease, no astigmatism of more than 3.5D. and no hyperopia of more than 5D., the following surprising atatements are probably true: Most persons, from 35 to 55 years of age, have a vision, either with or without accommo. dative effort, of $6 / 3$ to $6 / 6(20 / 10$ to $20 / 20)$, when looking through perfectly fitting reading lenses at distant test type; many persons, past 55 years of age, have a vision, in the entire absence of accommodative effort, of $6 / 6(20 / 20)$, when looking through perfectly-fitting reading lenses at distant test type.

It is probable that from 40 to 80 per cent. of persons have, in one or both eyes, $0.5 \mathrm{D}$. or more of astigmatism; and that from 30 to 70 per cent. of persons have a difference of $0.25 \mathrm{D}$. or more in the refraction of the eyes. Latent ametropia sometimes exists as late in life as the sixty-fifth year.

Few persons past 40 years of age are given lenses for the correction of astigmatism. Many with astig. matism of $0.5 \mathrm{D}$. or more have their lenses changed every two or more years, and go through life without any part of the astigmatism being discovered.

From experience it may be observed that many persons, with complicated ametropia, undergo the examinations of several oculists, no two of whom prescribe the same lenses, notwithstanding the refraction of the eyes is purely mechanic, the lenses only supplying the defects in the conformation and size of the eyes, whioh should be found to be the same in all examinations, if properly made.

The following proposition may show the need of the cylindric lens in the correction of the estigmatic eye: A given eye of a presbyope, of say 60 years of age, is perfectly fitted for reading with a compound lens +3 S. combined with +1 C. axis 98 . With this lens reading for hours is comfortable. Such an eye can read Jäger No. 1 at $22 \mathrm{~cm}$. ( 8.5 inches) with no weaker simple lens than $+4.5 \mathrm{D}$, with which reading for more than half an hour is not comfortable. The mean strength or convexity of the compound lens is $3.5 \mathrm{D}$, a gain of $1 \mathrm{D}$, , or, according to the rule as to years and diopters, a gain of about five years in favor of the compound lens.

In conclusion, it may be well to add that an im. proper astigmatic correction, or an antigmatic correction on a non-astigmatic eye, is more injurious than a spheric lens on an astigmatic eye.

\section{WHERE ARE WE AT?* \\ BY AP MORGAN VANCE, M.D. LOUISYILLE, $K Y$.}

In the last several months there has been much discussion pro and con of the commission evil, i. e., the mutual arrangement between the general practitioner and the specialist for a division of fees accruing from work which has been referred from one to the other. It would seem that this discussion followed an article in the Colorado Medical Journal, last July, by Dr. Melville Black, a specialist of Denver, Colo., who under certain conditions advocated the payment by the specialist to the practitioner of a portion of the fees obtained by him from patients referred.

Feeling that this society is representative and should not be behindhand in anything pertaining to our work, I thought it fit to bring this matter up for discussion to-night. If any of us are guilty of these practices, the free discussion of them may do us good in causing us to see the error of our ways; if we are innocent, the result of the discussion may do good to others. I will quote Dr. Black's paper in full and give some of the ideas of other men from different sections on the subject, with some comments of $\mathrm{my}$ own, as we progress Dr. Black's paper is as follows:

SHOULD THE GENERAL PRACTITIONER RECEIVE A FEE FOR REFERRING CASES TO THE SPECIALIST?

It may seem to a certain few that such a subject should be left out of print. I do not consider it a delicate question, nor one that is best discussed sub rosa. I believe that in a certain number of cases the physician should receive a fee for referring cases to the specialist.

The general practitioner is called upon to render every kind of medical and surgical service. If he sees fit to send certain cases to a specialist he displays a magnanimity unparalleled in other fields of labor. We will admit that in many instances his training and equipment are inadequate in some of the departments now presided over by specialists. The advancement of medicine and surgery has made it difficult for any one man to keep abreast of the entire field. He frequently recog. nizes that his knowledge in some one department is deficient. He is honest and tells the patient so. The patient is sent to a specialist. There are many instances where the practitioner has found it advisable to administer to his patient for several days before it is possible to refer him to a epecialist. Again, in his anxiety for the welfare of his patient he may make several visits in the endeavor to cause the latter to consult the specialist, or may lose valuable time in going with him to the epecialist. In any event he expends a certain amount of his *Read before the Louisville Medico-Chirurgical Society, March 10, 